\title{
Examination of the quality of Engelli bireye sahip life according to the physical ebeveynlerin fiziksel aktivite activity status of parents who durumlarına göre yaşam have disabled individual kalitelerinin incelenmesi ${ }^{1}$
}

\author{
Gizem Karakaş $^{2}$ \\ Çetin Yaman ${ }^{3}$
}

\begin{abstract}
In this research it was aimed to examine of the quality of life according to physical activity status of parents who have disabled individual. In the study using the descriptive survey model, convenience sampling was used for the creation of the sample. The parents of 164 disabled individuals(132 mother; $\bar{x}=40,5 \pm 8,90)$ ve 32 father; $\bar{x}=46,21 \pm 9,74)$ who attended to various special education institutions in Sakarya province participated in the research. The children of the participating families have autism, mental, visual, hearing and physical disabilities. In this study, a Family Information Form, which was prepared by the researcher, was used to reach the demographic informations of parents. With the aim of measuring the quality of life in parents, World Health Organization Quality of Life-Bref Form (WHOQOL-BREF), which was adopted to Turkish by Eser and his friends (1999) and for measuring the level of physical activity of parents, International Physical Activity Questionnaire-Short Form (IPAQ), which was adoped to Turkish by Öztürk (2005) were used in the study. All data were collected by face-toface interview technique. WHOQOL-BREF scale consists of 5 sub-dimensions including the physical area, psychological area, social area, environmental area and environmental TR area created by adding a question in Turkish
\end{abstract}

Özet

$\mathrm{Bu}$ araşturmada, engelli bireye sahip ebeveynlerin fiziksel aktivite durumlanna göre yaşam kalitelerinin incelenmesi amaçlanmıştır. Tarama modeli kullanılan çalışmada, örneklemin oluşturulmasinda kolayda örnekleme yönteminden yararlanılmıştır. Araştırmaya Sakarya ilinde çeşitli özel eğitim kurumlarına devam eden 164 engelli bireyin ebeveynleri (132 anne ve 32 baba) katılmıştır. Çalışmaya katılan ailelerin çocukları otizm, zihinsel, görme, işitme, bedensel engele sahiptirler. Kişilerin demografik bilgilerine ulaşma amaçlı araştırmacı tarafindan hazırlanan aile bilgi formu, ebeveynlerin yaşam kalitesini ölçmeye yönelik Eser vd.'nin (1999) Türkçe'ye uyarladığı Dünya Sağlık Örgütü Yaşam Kalitesi Ölçeği-Kısa Formu (WHOQOL-BREF) ve ebeveynlerin fiziksel aktivite düzeylerini ölçmek için Öztürk'ün (2005) Türkçe’ye uyarladığı Uluslararası Fiziksel Aktivite Anketi-Kısa Form (IPAQ) kullanılmıştır. Tüm veriler yüz yüze görüşme tekniği ile toplanmıştır. WHOQOL-BREF ölçeği bedensel alan, ruhsal alan, sosyal alan, çevresel alan ve Türkçe'ye uyarlamada bir sorunun eklenmesiyle oluşturulan çevresel TR alan olmak üzere toplam 5 alt boyuttan ve 27 sorudan oluşmaktadır. Alt boyutlara ait iç tutarlılik katsayıları sirasiyla, .77, .71, .61, .81, .78 olarak tespit edilmiştir. IPAQ ölçeği yürüme, orta-şiddetli ve şiddetli aktivitelerde harcanan zaman hakkında bilgi vermektedir ve skorunun

\footnotetext{
${ }^{1}$ Sakarya University Institute of Educational Science Physical Education and Sport Teaching Master Thesis.

${ }^{2}$ Res. Assist., Sakarya University Faculty of Sport Sciences, Department of Recreation, gdogduay@sakarya.edu.tr

${ }^{3}$ Assoc. Prof. Dr., Sakarya University Faculty of Sport Sciences, Department of Recreation, cyaman@sakarya.edu.tr
} 

incelenmesi. Journal of Human Sciences, 14(1), 724-737. doi:10.14687/ihs.v14i1.4287

adaptation and 27 questions. The Cronbach's alpha coefficient of physical area subscale is .77., psychological area subscale is .71 , social area is .61 , environmental area is .81 and environmental area Turkey is .78. IPAQ self-administered 'last 7 days' short form was used in this study. The form provides information on time spent on walking, moderate-severe and violent activities. The calculation of the total score of the short form is based on the sum of time (minutes) and frequency (days) (Öztürk, 2005). After the descriptive statistical processes had been applied in the analysis of datas, an independent t-test and chi-square test to detect from which groups the differences between the groups originate. Data was evaluated by using SPSS for Windows 15 software.

As a result, the fact that the quality of life parents who have disabled individual and doing sport was found to be at a higher level of those who have individual but not doing sport. In addition to this doing sport was detected to increase the quality of life parents who have a disabled individual. As a result, it is thought that the parents of physically active parents have higher quality of life and physical activity levels and as a result they will provide a better and healthier life for their children. Their families are thought to be the first step in raising awareness and guiding them in order to enable them to live as healthy families and to raise healthy individuals.

Keywords: Quality of life; parents; disabled individual; physical activity.

(Extended English abstract is at the end of this document) hesaplanması süre (dakika) ve frekans (gün) toplamindan yapılmaktadır. Elde edilen verilerin analizinde betimsel istatistiksel işlemler uygulandiktan sonra, değişkenler arası farkllıkları ölçmek amaciyla independent samples t-test ve ki-kare testi yapılmıștır. Veriler SPSS 15.0 programında değerlendirilmiş ve anlamlllk düzeyi olarak 0.05 kullanılmıştır. Analiz sonuçları incelendiğinde, fiziksel aktivite yapan engelli bireye sahip ebeveynlerin bedensel alan hariç tüm alanlarının ve fiziksel aktivite düzeylerinin fiziksel aktivite yapmayanlardan yüksek olduğu bulunmuştur. Dolayısıyla fiziksel aktivitenin ruhsal, sosyal, çevresel yaşam kalitesini olumlu yönde etkilediği ve fiziksel aktivitenin engelli bireye sahip ebeveynlerin yaşam kalitesini yükselttiği söylenebilir. Sonuç olarak, fiziksel aktivite yapan ebeveynlerin yaşam kalitelerinin ve fiziksel aktivite düzeylerinin daha yüksek olduğu buna bağlı olarak da çocukları için daha güzel ve sağlıklı bir yaşam sunabilme imkânları olacağı düşünülmektedir. Aileleri bu konuda bilinçlendirmek ve yönlendirmek onların daha sağlıklı aileler olarak yaşamasına ve sağlıklı bireyler yetiştirmesine imkân sağlamak için atılması gereken ilk adım olarak düşünülmektedir.

Anahtar Kelimeler: Yaşam kalitesi; ebeveyn; engelli birey; fiziksel aktivite.

\section{Giriş}

Yaşam kalitesi, sağlıkla ilgili özel durumları da içeren ilişkisel, psikolojik ve fiziksel bakış açıları gibi çoklu etki alanlarını kapsayan iyi olma hali ve sağlıktan daha fazlasını içeren çok boyutlu bir kavramdır (Lee vd., 2009). Yaşam kalitesi içinde bulunulan durumu ifade etmek için kullanılan yaşam standardı, yaşam biçimi, yaşam koşulları, refah, iyilik, mutluluk, sağlık, huzur gibi deyimlerle birlikte kullanılabilmektedir (Sapancalı, 2009:14).

İnsanların tüm gelişim alanlarının temelinin atıldığı aile, yaşam kalitesi düzeyinin oluşmaya başladığı yer olarak düşünülmektedir. Ailenin kendi doğası gereği içinde oluşan olumlu ya da olumsuz duygular kişileri etkileyebilir ve yaşam kaliteleri üzerinde rol oynayabilir. Bu kapsamda değerlendirilen aile yaşam kalitesi, aile üyelerinin ihtiyaçlarının karşılanması, bir aile olarak birlikte 
Karakaş, G., \& Yaman, Ç. (2017). Engelli bireye sahip ebeveynlerin fiziksel aktivite durumlarına göre yaşam kalitelerinin incelenmesi. Journal of Human Sciences, 14(1), 724-737. doi:10.14687/jhs.v14i1.4287

yaşama, aile bireyleri için anlam taşıyan hedeflere sahip olma ve bunlara ulaşma şeklidir (Boylu ve Terzioğlu, 2007:30).

Ailenin oluşmasında önemli bir rol oynayan normal bir çocuğun doğumu, anne ve babanın birçok yenilik ve alışılması zor olan koşullar ile karşılaşmasına yol açar. Ancak koşullara ek olarak, aileye kattlan yeni bireyin engelli olması, ailede şok etkisi yaratarak normal aile yaşamının bozulmasına (Özşenol vd., 2003) ve aile için bir krize (Sevindi vd., 2010) neden olabilmektedir. Ebeveynler engelli çocuklarıla ilgili olarak, aile ve toplum tarafindan kabul görememe, topluma kazandıramama ve normal gelişim gösteren çocuklar gibi bir birey olarak karşılanamama sorunları yaşamaktadırlar. Bu sorunlar hem çocukları hem de ebeveynleri olumsuz yönde etkilemektedir. Aileye kattlan engelli çocuk ya da sonradan engelli olan birey anne ve babaya ek stres kaynağ1 oluşturmaktadır. Bu duygu ve düşüncelerde oluşan ek stres kaynağının nedenlerinden birinin toplumda alışılagelmiş bir engellilik algısından kaynaklanan baskı olduğu düşünülmektedir.

Toplumun, engelli bir birey gördüğü zaman acıma, yanına yaklaşmama, "Benim çocuğuma da bulaşır mı?” düşüncesi gibi önyargıları ile ebeveynler üzerinde oluşturdukları psikolojik baskı çok yıpratıcı olmaktadır. Engelli çocuğa sahip olmanın "Toplumda nasıl karşılanır?” düşüncesi bir yana dursun; ebeveynlerin kendi içinde bu durumu kabullenmesi ve üstesinden gelmesinin oldukça zor bir süreç olduğu söylenebilir. Çünkü engelli bir çocukla yaşamak, aile bireylerinin planlarını, gelecekle ilgili projelerini ve beklentilerini değiştirmektedir (Aysan ve Özben, 2007). Aile beklentisi ve aile işlevselliğinin gerçeği arasındaki tutarsızlık, ebeveynlerde zihinsel sağlığın zayıflamasına yol açmaktadır (Johnson vd., 2011). Sahip olduğu tüm sınırllıkları ailesine direkt ya da dolaylı olarak yansıtan engelli bireye sahip olmak, ebeveynlerin yapmak istedikleri birçok şeyi erteledikleri veya tamamen iptal ettikleri süreçte sosyal yaşamını, aile içi yaşamını, iş yaşamını kısacası tüm yaşamını etkileyebilmektedir. Kayg1, depresyon ve stresle birlikte gelen bu olumsuz etkilenme, ailenin yaşama tutunmak için gerekli olan hayattan keyif alma imkânları, motivasyonları, özverileri gibi gerekli psikolojik ihtiyaçların karşılanmasını da sınırlandırarak yaşam kalitesini olumsuz etkilemektedir (Özşenol vd., 2003; Özay, 2004; Aysan ve Özben, 2007). Bu nedenle, rehabilitasyonun hedefleri arasında engelli bireyin olduğu kadar, engelliye bakım veren kişinin de sağlıkla ilgili yaşam kalitesinin geliştirilmesi yer almalıdır (Vergili, Oktaş ve Koçulu, 2015). Dardas ve Ahmad (2014a) çalışmalarında otizmli çocuğa sahip olmanın ebeveynler üzerinde büyük etkisi olduğunu ve bu etkilerin ebeveynlerin stres düzeyleri, başa çıkma becerileri, kişisel özellikleri ve içinde bulundukları kültürel şartlara bağlı olduğunu belirtmişlerdir. Çalışmalar da gelişimsel bozukluğa sahip çocukların annelerinin, normal gelişim gösteren çocuklara sahip annelerden daha düşük fiziksel sağlık ve yaşam kalitesi olduğunu göstermektedir (Allik vd., 2006; Brown vd., 2006; Mugno vd., 2007; Benjak, 2011; Aras vd., 2014; Eapen ve Guan, 2016). Engelli veya otizmli çocuğu büyütmek, çocuğun uyum becerilerini, karakteristik özelliklerini, algılanan aile yaşam kalitesini, psikolojik sağllğını ve ailenin tutarlık duygusunu etkileyebilmektedir (Baghdadli vd., 2014; Pozo vd., 2014; Tung vd., 2014). Bu noktada, ailenin tutarlık duygusu ve sosyal desteği duygusal sağlığın ve yaşam kalitesinin artması için hayati öneme sahiptir (Ngai ve Ngu, 2013).

Toplumların refah ve mutlulukları ile ailelerin refah ve mutlulukları arasında doğrudan pozitif bir ilişki olmakla birlikte (Boylu ve Terzioğlu, 2007;20); refah düzeyinin aile işlevine pozitif etkisi bulunmaktadır (Kalkavan vd., 2011). Ayrıca ailelerinin kendi sağlıkları, çocuklarının engeliyle başetmede en güçlü etkendir (Chouvd., 2007). Bu nedenle, iletişim ve etkileşim, topluma uyum sağlama, sağlıklı ruh hali gibi gerekli olan sosyal deneyimlerin kazanıldığı ailede, anne ve babanın sağlıklı birer kişilik yapısına ve psikolojisine sahip olması, çocuklarına olan davranışlarına da sağlıkla yansıyacağından (Çalışkan, 2011) ailenin yüksek yaşam kalitesine sahip olmasının yetiştireceği çocuklarının genel sağlığ1 üzerine de olumlu etki edeceği düşünülmektedir. Çünkü ailenin yaşam kalitesinin düşük olması, aile içi refahın, huzurun ve sağllğın olmaması, ailede yetişen çocuğun da bundan olumsuz etkilenerek büyümesine neden olabilir. Aile içi çatışmaları, anne ve babanın bozuk ruh hali, fiziksel sağlıklarının çocuklarıyla verimli zaman geçirebilecek düzeyde olmaması, çocuğun gelişimsel anlamda geri kalmasına yol açabilir. Zira çocuğun okulda aldığı eğitimin öğrenmenin kalıcılı̆̆ı açısından ailede tekrarlanarak pekiştirilmesi ve ailenin bu konuda yardımcı olması 
Karakaş, G., \& Yaman, Ç. (2017). Engelli bireye sahip ebeveynlerin fiziksel aktivite durumlarına göre yaşam kalitelerinin incelenmesi. Journal of Human Sciences, 14(1), 724-737. doi:10.14687/jhs.v14i1.4287

gerekmektedir. Tüm alanlarıyla çocuğa yetemeyen, sağlıksız ve mutsuz bir ailenin çocuğunun da aynı şekilde olacağı şüphesizdir.

Yüksek yaşam kalitesine sahip olmanın temel araçlarından biri de fiziksel aktivite olduğundan; bu düşüncenin bilinçli olarak yaygınlaşmasında, toplumsal bir boyut kazanmasında ve sağlıklı nesillerin yetişmesinde ailelerin spora olan ilgi ve bilgi düzeyleri etkili olmaktadır (Yıldız ve Şentürk, 2010). Fiziksel aktivite ile birlikte içinde bulunulan olumsuz duyguları en aza indirmek, fiziksel aktivitenin verdiği huzur, sağllk ve zihin açılımılla çocuğu yetiştirmek, hem çocuğun özgüven kazanması hem sağlıklı gelişmesi hem de topluma kazandırılması noktasında güçlü bir sebep olabilir. Annenin özellikle de sağıkla ilişkili yaşam kalitesinin iyileştirilmesi çocuğun daha iyi bakım almasını sağlayarak, fonksiyonel bağımsızlık düzeyini ve yaşam kalitesini de artıracaktır (Vergili, Oktaş ve Koçulu, 2015).

Yaşam kalitesi ve birçok psikolojik faktörü iyileştirmek adına, ebeveyn ve engelli çocuk farklı aktivitelere yönelerek hem aile içinde hem de toplum içinde yaşadığ sorunlarından uzaklaşabilir. Bu aktivitelerden biri olan ve ebeveynlerin yaşam kalitelerine pozitif bir dokunuş teşkil eden fiziksel aktivite; ebeveynlerin katılabileceği, rekreasyonel amaçlı ya da uzmanlaşarak profesyonel olarak yapabileceği, sosyal, fiziksel, zihinsel ve psikolojik olarak rahatlayıp yenilenmesine imkân sağlayan temel bir alandır. Fiziksel aktivite, aynı zamanda bu yenilenmelerle yaşam kalitesini de yükselten, aileleri mutlu ve huzurlu kılan bir yaşam biçimidir. Fiziksel aktiviteleri beraber gerçekleştiren aile bireyleri farklı ve yoğun bir iletişimde bulunurlarken; fikir ayrılıkları, iletişim engelleri, kabullenme ve olumsuz duygular gibi sorunların aşılmasında da önemli yol alacakları düşünülmektedir. Çünkü engelli çocuğa bakım veren kişinin yaşam kalitesinde etkili bir iletişimin önemli olduğu bilinen bir gerçektir (Aras vd., 2014). Karademir vd.'na (2011) göre spora katılan bireyin, yeterlik duygusu, özgüven, bir gruba ait olma ve kabul görme hissi, çevresini tanıma ve iletişim kurabilme becerilerinde olumlu gelişmeler görülür. $\mathrm{Bu}$ da duygusal olarak daha iyi ruh hali yaşamasına olanak sağlar. Aynı zamanda spor yoluyla sosyalleşmek, insanlar arasında menfaatsiz bir yakınlı̆ı̆n doğmasıyla birlikte insancıl kaynaşmayı sağlamaktadır (Arslan, Güllü ve Tutal, 2011).

Tüm bu etkenler düşünüldügünde, ailenin fiziksel aktivite ile beraber yükselen yaşam kalitesi anlayışının çocuklarına da olumlu yönde yansıyacağı düşünülmektedir. Ailelerin her açıdan sağlıklı olması sağlıklı çocuklarının da sağlıklı yetişmesine yol açacaktır. Çocukların hayata dair beklentilerini karşılayabilecek, tatminini sağlayabilecek ve memnuniyetsizlikten uzakta yaşayabilecek, tüm gelişimsel alanlarda kendine yetebilcek bir güçle yaratıcı ve yapıcı olma çabası içinde (Sapancalı, 2009;11) yetişmesine olanak sağlayacaktır. Fiziksel aktivite disiplini ve gerekliliği düşüncesiyle yetişen çocukların hayatlarında da fiziksel aktivite yapmanın kazandırmış olacağı fiziksel, ruhsal ve sosyal davranış alışkanlığı, yüksek yaşam kalitesini bereberinde getirecektir. Bu nedenle ailelerin yaşam kalitelerinin yükseltilmesi yönündeki her çalışma sağlıklı bir topluma ulaşmada önem taşımaktadır (Boylu ve Terzioğlu, 2007;20).

Engelli ve otizmli bireylerin ailelerinin yaşam kalitesinin araştırıldı̆̆ pek çok araştırma mevcut iken (Leung ve Li-Tsang 2003; Allik vd., 2006; Aysan ve Özben 2007; Erdoğanoğlu ve Kerem Günel, 2007; Mugno vd. 2007; Chou, vd. 2007; Lin, 2009; Benjak, 2011; Dardas ve Ahmad 2013; Modesta Pousadavd. 2013; Marchal vd. 2013; Gomez ve Gomez, 2013; Eapen, Črnčec, Walter, veTay, 2014; Meral ve Cavkaytar, 2014; Dardas ve Ahmad 2014a; Dardas ve Ahmad 2014b; SiahveTan, 2016; Eapen ve Guan, 2016); bu kitle üzerinde yaşam kalitesini spor bilimleriyle ilişkilendirerek araştıran çalışmalara rastlanamamıştır. Yapılan çalışmalar sadece mevcut durum üzerine yapılmış herhangi bir etki yaratacak değişkenle ilişkilendirilmemiştir. Bu çalışmada, fiziksel aktivite yapmanın engelli bireye sahip ailelerde önemine değinilmek istenmiş ve fiziksel aktivitenin hem aile için hem de ebeveynlerin çocuklarına daha verimli davranış kazanmaları için ne denli önemli olduğu anlatılmaya çalışılmışır. Bu açıdan; araştırmada, engelli bireye sahip ebeveynlerin fiziksel aktivite durumlarına göre yaşam kalitelerinin incelenmesi amaçlanmıştır.

Ailelerin fiziksel durumlarının ortaya konarak, onların bu konu hakkında bilinçlenmesi, fiziksel aktivitenin bedensel etkisinin yanı sira psikoljik, sosyal ve zihinsel sağlık için de önemli ve etkili bir süreç olduğunun aktarılması adına çalışmanın önem arz ettiği düşünülmektedir. $\mathrm{Bu}$ 
Karakaş, G., \& Yaman, Ç. (2017). Engelli bireye sahip ebeveynlerin fiziksel aktivite durumlarına göre yaşam kalitelerinin incelenmesi. Journal of Human Sciences, 14(1), 724-737. doi:10.14687/jhs.v14i1.4287

düşünceden yola çıkılarak cevap alınması istenen ana problem, engelli bireye sahip spor yapan ve yapmayan ebeveynlerin yaşam kaliteleri ve MET değerleri arasında farklılık olup olmadı̆̆ ve ebeveynlerin fiziksel aktivite durumlarına göre yaşam kalitelerinin nasıl olduğu konusudur.

\section{Yöntem}

Araştırmada, geçmişte ya da halen varolan bir durumu varolduğu şekliyle betimlemeyi hedef alan genel tarama modelinden tekil tarama modeli (Karasar, 2015;77) kullanılmıştır. Çalışmaya dahil olan 164 engelli bireye sahip ebeveyn (132 anne ve 32 baba) kolayda örnekleme yönteminden yararlanılarak oluşturulmuştur. Çalışmaya katılan ailelerin çocukları otizm, zihinsel, görme, işitme ve bedensel engele sahiptirler. Araşturmada, engelli bireye sahip ebeveynlerin fiziksel aktivite durumlarına göre yaşam kalitelerinin incelenmesi amacıylaaraştırmacı tarafindan hazırlanan "Aile Bilgi Formu", "Dünya Sağlık Örgütü Yaşam Kalitesi Ölçeği-Kısa Form (WHOQOL-BREF)" ve "Uluslararası Fiziksel Aktivite Anketi-Kısa Form (IPAQ)" kullanılmıştır.

Bireylerin kendi yaşam kalitelerini nasıl algıladıklarını değerlendirmek üzere Dünya Sağlık Örgütü (DSÖ) Yaşam Kalitesi Grubu tarafindan 1996 yllında geliştirilen ölçek; 100 sorudan oluşan WHOQOL-100 (uzun) ve bu 100 sorudan seçilen 26 soruyla oluşan WHOQOL-BREF (kısa) formlarına sahiptir (Tekkanat, 2008). Çalışmada Türkçe geçerlilik ve güvenilirlik çalışması Eser vd. (1999) tarafindan yapılan Kısa Formu (WHOQOL-BREF) kullanılmıştır. Ölçek bedensel alan, ruhsal alan, sosyal alan, çevresel alan ve Türkçe'ye uyarlamada bir sorunun eklenmesiyle oluşturulan çevresel TR (Türkiye) alan olmak üzere toplam 5 alt boyuttan ve 27 sorudan oluşmaktadır. Ölçekte 3., 4., 26., ve 27. sorular ters kodlanarak puanlandırlmaktadır. Ölçeğe ait alt boyutların iç tutarlık kat sayıları bedensel alan için .77, ruhsal alan için .71, sosyal alan için .61, çevresel alan için .81 ve çevresel TR alanı için .78 olarak bulunmuştur.

Çalışmada kullanılan diğer ölçüm aracı olan Uluslararası Fiziksel Aktivite Anketi-Kısa Formu, Dünya Sağlık Örgütü ve Hastalığın Kontrolü ve Korunma Merkezi tarafindan geliştirilmiş ve Türkçe geçerliği ve güvenirliği Öztürk (2005) tarafindan yapılmıştır. Anketin farklı formları mevcut olmakla birlikte bu çalışmada kendi kendine uygulanabilen 'son 7 gün' kısa formu kullanılmıştır. Form, yürüme, orta-şiddetli ve şiddetli aktivitelerde harcanan zaman hakkında bilgi vermektedir. Kısa formun toplam skorunun hesaplanması süre (dakika) ve frekans (gün) toplamından yapılmaktadır (Öztürk, 2005). Bu hesaplamalardan, MET-dakika olarak bir skor elde edilmektedir ve fiziksel aktivite esnasında tüketilen oksijen miktarını ifade etmek için Metabolic Equivalent (metabolik eşdeğer -istirahat metabolik hızı) kısaltılmışı olan MET terimi kullanılır (Zorba ve Saygin, 2009).Cengiz'e göre, (2007) düşük grup (sedanter, inaktif) egzersize katılımı 600 MET-dk/hafta' dan daha az katılımcıları; orta düzeydeki fiziksel aktivite grubu, egzersize katılımı 601-3000 MET-dk/hafta arasındaki katılımcıları; fiziksel olarak aktif grup ise (yüksek, tavsiye edilen seviye) egzersize katılımı 3000 MET-dk/hafta' dan daha fazla olan katılımcıları içerir.

Veriler, araştırmacı tarafından, engelli çocukların eğitim gördükleri okullara gidilerek, ailelerle yüz yüze görüşme tekniğiyle çocuklarının ders saatleri içerisinde uygulanmıştır. Elde edilen verilere frekans (f) ve yüzde (\%) hesaplaması, değişkenler arası farklıllğı belirlemeye yönelik independent samples t-test ve ki-kare testi yapılmıştır. Ki-kare, iki ya da daha çok grup arasında niteliksel yönden fark olup olmadığını incelemek için kullanılır (Alpar, 2010; 174). Elde edilen veriler SPSS 15.0 programında değerlendirilmiştir ve anlamlılık düzeyi olarak 0.05 ele alınmıştır.

\section{Bulgular}

Araştırmaya 132 anne $(\bar{x}=40,5 \pm 8,90)$ ve 32 baba $(\bar{x}=46,21 \pm 9,74)$ olmak üzere toplam katılan 164 ebeveyn katılmıştır. Çalışmaya katılan ebeveynler otizmli (\%25.6), zihinsel (\%41.5), görme (\%2.4), işitme (\%15.2) ve bedensel engelli (\%15.2) çocuk sahip olmalarına yönelik olarak çalışmaya dahil olmuşlardır. Bu bölümde çalışmayla ilgili bulgular yer almaktadır. 
Karakaş, G., \& Yaman, Ç. (2017). Engelli bireye sahip ebeveynlerin fiziksel aktivite durumlarına göre yaşam kalitelerinin incelenmesi. Journal of Human Sciences, 14(1), 724-737. doi:10.14687/jhs.v14i1.4287

Tablo 1. Ebeveynlerin fiziksel aktivite bilgileri frekans ve yüzde değerleri

\begin{tabular}{|c|c|c|}
\hline & $\mathrm{n}$ & $\%$ \\
\hline \multicolumn{3}{|l|}{ Fiziksel Aktivite Durumları } \\
\hline Evet & 61 & 37.2 \\
\hline Hayır & 103 & 62.8 \\
\hline Toplam & 164 & 100 \\
\hline \multicolumn{3}{|l|}{ Fiziksel Aktivite Türü } \\
\hline Yürüyüş & 22 & 13.4 \\
\hline Yüzme & 13 & 7.9 \\
\hline Koşu & 8 & 4.9 \\
\hline Fitness & 6 & 3.7 \\
\hline Futbol & 5 & 3 \\
\hline Pilates & 3 & 1.8 \\
\hline Tenis & 1 & .6 \\
\hline Basketbol & 1 & .6 \\
\hline Voleybol & 1 & .6 \\
\hline Kayak & 1 & .6 \\
\hline Toplam & 61 & 37.2 \\
\hline \multicolumn{3}{|c|}{ Fiziksel Aktivite Yapma Amacı } \\
\hline Kilo vermek için & 12 & 7.3 \\
\hline Sağllk için & 40 & 24.4 \\
\hline Stresten uzak durmak için & 9 & 5.5 \\
\hline Toplam & 61 & 37.2 \\
\hline \multicolumn{3}{|c|}{ Fiziksel Aktivite Yapma Sıklığ1 } \\
\hline Her gün & 13 & 7.9 \\
\hline Gün aşır1 & 9 & 5.5 \\
\hline Haftada bir kez & 34 & 20.7 \\
\hline Ayda bir kez & 5 & 3 \\
\hline Toplam & 61 & 37.2 \\
\hline \multicolumn{3}{|c|}{ Fiziksel Aktivite Yapmama Nedeni } \\
\hline Zamanim yok & 37 & 22.6 \\
\hline Çocuğuma bakmak için & 17 & 10.4 \\
\hline Gerek duymuyorum & 17 & 10.4 \\
\hline Sağlık sorunlarım var & 9 & 5.5 \\
\hline İş yoğunluğu & 9 & 5.5 \\
\hline Yaşlilik & 8 & 4.9 \\
\hline Ev işleri & 6 & 3.7 \\
\hline Toplam & 103 & 62.8 \\
\hline
\end{tabular}

Ebeveynlerin \%32.7'si fiziksel aktivite yaptıklarını belirtirken, büyük çoğunluğu \%62.8 ile fiziksel aktivite yapmadıklarını belirtmişlerdir. Fiziksel aktivite yapan 61 ebeveynden 22'sinin verdiği yürüyüş cevab1 \%13,4'lik bir oranla en çok tercih edilen aktivite olmuştur. Yürüyüş aktivitesini; yüzme, koşu, fitness, futbol ve pilates aktiviteleri takip etmektedir. Çalsşmada tenis, basketbol, voleybol ve kayak en az tercih edilen aktiviteler arasında yer almaktadır. Bu ebeveynlerden \%24’ü sağlık için, \%7.3’ü sağlık için ve \%5.5’luk kısmı ise stresten uzak durmak için fiziksel aktivite yapmayı tercih ettiklerini belirtmişlerdir. Ebeveynlerin fiziksel aktivite yaptıkları sıklık düzeyleri ise haftada bir (\%20.7), her gün (\%7.9), gün aşırı (\%5.5) ve ayda bir (\%3) olarak değişkenlik göstermektedir. 103 ebeveynin fiziksel aktivite yapmamalarına ilişkin öne sürdügü nedenler arasında çoğunlukla "zamanım yok" (\%22) cevabı yer almıştır. 
Karakaş, G., \& Yaman, Ç. (2017). Engelli bireye sahip ebeveynlerin fiziksel aktivite durumlarına göre yaşam kalitelerinin incelenmesi. Journal of Human Sciences, 14(1), 724-737. doi:10.14687/jhs.v14i1.4287

Tablo 2. Yaşam kalitesi WHOQOL-BREF ölçeği alt boyutları ortalama puanları ve değerleri

\begin{tabular}{lcccccc}
\hline & $\mathrm{n}$ & Min. & Maks. & $\bar{x}$ & SS & $\alpha$ \\
\hline Bedensel Alan & 164 & 7.43 & 20.00 & 13.86 & 2.46 & .77 \\
Ruhsal Alan & 164 & 6.00 & 19.33 & 13.82 & 2.21 & .71 \\
Sosyal Alan & 164 & 4.00 & 20.00 & 13.87 & 2.85 & .61 \\
Çevresel Alan & 164 & 4.50 & 19.50 & 13.39 & 2.54 & .81 \\
Çevresel TR Alanı & 164 & 4.44 & 19.11 & 13.35 & 2.30 & .79 \\
\hline
\end{tabular}

Yaşam kalitesi alt boyutlarından alınan ortalama puanlar ve değerlerin gösterildiği tablo 2'de alt boyutlardan alınan ortalama puanların birbirine yakın sonuçlar verdiği görülmekle birlikte en yüksek ortalamaya sahip sosyal alan $(13.87 \pm 2.85)$ ve en düşük ortalamaya sahip çevresel TR alan (13.35 \pm 2.30$)$ olduğu görülmüştür. Ölçeğin iç tutarlık katsayıları, bedensel alan için .77, ruhsal alan için .71, sosyal alan için .61, çevresel alan için .81 ve çevre TR alanı içinse .79 olarak bulunmuştur.

Tablo 3. Ebeveynlerinfiziksel aktivite durumlarına göre yaşam kaliteleri arasındaki farklar

\begin{tabular}{|c|c|c|c|c|c|c|}
\hline & $\begin{array}{c}\text { Ebeveynlerin Fiziksel } \\
\text { Aktivite Durumu }\end{array}$ & $\mathrm{n}$ & $\bar{x}$ & SS & $\mathrm{t}$ & $\mathrm{p}$ \\
\hline \multirow{2}{*}{ Bedensel Alan } & Evet & 61 & 14.26 & 2.32 & \multirow{2}{*}{1.624} & \multirow{2}{*}{.106} \\
\hline & Hayır & 103 & 13.61 & 2.52 & & \\
\hline \multirow{2}{*}{ Ruhsal Alan } & Evet & 61 & 14.36 & 1.95 & \multirow{2}{*}{2.447} & \multirow{2}{*}{$.015^{*}$} \\
\hline & Hayır & 103 & 13.50 & 2.29 & & \\
\hline \multirow{2}{*}{ Sosyal Alan } & Evet & 61 & 14.65 & 2.55 & \multirow{2}{*}{2.816} & \multirow{2}{*}{$.005^{*}$} \\
\hline & Hayır & 103 & 13.40 & 2.92 & & \\
\hline \multirow{2}{*}{ Çevresel Alan } & Evet & 61 & 14.00 & 2.57 & \multirow{2}{*}{2.403} & \multirow{2}{*}{$.017^{*}$} \\
\hline & Hayır & 103 & 13.03 & 2.47 & & \\
\hline \multirow{2}{*}{ Çevresel TR Alanı } & Evet & 61 & 13.87 & 2.296 & \multirow{2}{*}{2.256} & \multirow{2}{*}{$.025^{*}$} \\
\hline & Hayır & 103 & 13.04 & 2.253 & & \\
\hline
\end{tabular}

Tablo 3 incelendiğinde çalışmaya katılan engelli çocuğa sahip ebeveynlerinfiziksel aktivite değişkenine göre analiz sonuçlarında ruhsal alan, sosyal alan, çevresel alan, çevresel TR alanı alt boyutlarında anlamlı bir farklılık olduğu görülmektedir $(\mathrm{p}<0.05)$.

Tablo 4. Ebeveynlerinfiziksel aktivite durumlarına göre MET değerlerinin ki-kare sonuçları

\begin{tabular}{|c|c|c|c|c|c|c|}
\hline \multirow{2}{*}{\multicolumn{2}{|c|}{$\begin{array}{l}\text { Ebeveynlerin Fiziksel } \\
\text { Aktivite Yapma Durumları }\end{array}$}} & \multicolumn{3}{|c|}{ MET } & \multirow{2}{*}{ Toplam } & \multirow[b]{2}{*}{$\mathrm{p}$} \\
\hline & & Düşük & Orta & Yüksek & & \\
\hline \multirow{2}{*}{ Evet } & $\mathrm{n}$ & 15 & 26 & 20 & 61 & \multirow{6}{*}{$.008^{*}$} \\
\hline & $\%$ & $\% 24.6$ & $\% 42.6$ & $\% 32.8$ & $\% 37.2$ & \\
\hline \multirow{2}{*}{ Hayır } & $\mathrm{n}$ & 48 & 38 & 17 & 103 & \\
\hline & $\%$ & $\% 46.6$ & $\% 36.9$ & $\% 16.5$ & $\% 62.8$ & \\
\hline \multirow{2}{*}{ Toplam } & $\mathrm{n}$ & 63 & 64 & 37 & 164 & \\
\hline & $\%$ & $\% 38.4$ & $\% 39$ & $\% 22.6$ & $\% 100$ & \\
\hline
\end{tabular}

Yapılan ki-kare analizi sonuçlarına göre fiziksel aktivite yapan engelli bireye sahip ebeveynler ile fiziksel aktivite yapmayan engelli bireye sahip ebeveynlerin MET değerleri arasında anlamlı bir farkl11ık bulunmuştur $(\mathrm{p}<0.05)$. Fiziksel aktivite yapan kişilerin en fazla orta MET (\%42.6) değerine sahip olduğu, bunu sırasıyla yüksek (\%32.8) ve düşük (\%24.6) MET değerlerinin takip ettiği görülmektedir. Ayrıca fiziksel aktivite yapmayan kişilerinse en fazla düşük MET (\%46.6) değerine sahip olduğu ve daha sonra orta (\%36.9) ve yüksek (\%16.5) MET değerlerinin geldiği görülmektedir. Ortaya çıkan farklılığın fiziksel aktivite yapan kişiler lehine olduğu saptanmıştır. 
Karakaş, G., \& Yaman, C.. (2017). Engelli bireye sahip ebeveynlerin fiziksel aktivite durumlarına göre yaşam kalitelerinin incelenmesi. Journal of Human Sciences, 14(1), 724-737. doi:10.14687/jhs.v14i1.4287

\section{Tartışma ve Sonuç}

Engelli bireye sahip ebeveynlerin fiziksel aktivite durumlanına göre yaşam kalitelerinin incelenmesi amacıyla yapılan çalışmada, engelli bireye sahip fiziksel aktivite yapan ebeveynlerin bedensel alan hariç tüm alanlarının ve fiziksel aktivite düzeylerinin (MET) engelli bireye sahip fiziksel aktivite yapmayan ebeveynlerden yüksek olduğu bulunmuştur. Dolayısıyla fiziksel aktivitenin ruhsal, sosyal, çevresel yaşam kalitesini olumlu yönde etkilediği söylenebilir. MET değerlerine ilişkin analiz sonuçlan da bu bulguyu destekler niteliktedir. Fiziksel aktivite yapan ebeveynlerin MET değerleri, yapmayan ebeveynlerin MET değerlerinden daha yüksek bulunmuştur. Fiziksel aktivite yapan ailelerin daha aktif bir hayat tarz1 tercih ettikleri söylenebilir.

Omorou, Erpelding, Escalon, Vuillemin'in de (2013) belirttiği üzere spor aktiviteleri, yaşam kalitesinin gelişiminde ve artmasında hatrı sayllır bir öneme sahiptir. Fiziksel aktivitenin ve spora katılımın tüm bireyler üzerinde olan olumlu etkisi göz ardı edilmemelidir. Spora katıllım tüm yaşam kalitesi alanlanını olumlu yönde etkilemekte (Altun vd., 2011) ve egzersizlerden sonra yaşam kalitesi gelişerek yükselmektedir (Spirduso ve Cronin, 2001; Elley vd., 2003; Fisher ve Li, 2004).

Dahan-Oliel, Shikako-Thomas ve Majnemer (2012) birçok çalışmada, hem engelli çocukların hem de ailelerinin evde, okulda ya da toplum içersinde hergün katıldığı serbest zaman aktivitelerinin sağllğ1 ve yaşam kalitesini yükseltmesi yönünde bulgular olduğunu söylemişlerdir. Aynı şekilde çalışmalarda aktivitelere katılmamak ya da katılımı azaltmak da yaşam kalitesinin düştügü yönünde sonuç vermiştir (Dahan-Oliel, Shikako-Thomas ve Majnemer, 2012). Ayrıca, zihin sağlığ1, sosyal işlevsellik, fiziksel sağlık ve zindelikle de fiziksel aktivitenin pozitif ilişki içinde olduğu belirtilmiştir. Yaş, eğitim düzeyi, sigara ve alkol kullanımı ve beden kütle indeksi ile ilişkilendirirlerek yapılan analizler sonucunda ev aktivitesi yapanların ve ulaşımı fiziksel olarak sağlayanların yaşam kalitesi daha yüksek bulunmuştur (Jurakic, Pedisic ve Greblo, 2010). Tessier vd., da (2007) bu düşüncelere ek olarak serbest zaman aktiviteleri ile sağlıkla ilişkili yaşam kalitesi arasında zihinsel alanla ilgili değişimlerin fiziksel alana göre daha fazla olduğunu belirtmiştir. Bu sonuçlar doğrultusunda, literatürle de uyumlu olarak, fiziksel aktivite yapan ile yapmayan ebeveynler arasında yaşam kalitesi açısından fark olduğu ve bu farklılığa bağlı olarak fiziksel aktivitenin yaşam kalitesini yükselttiğini söylemek mümkündür.

Otizmli çocuğu bulunan annelerin yaşam kalitesi ve ruh sağlı̆̆ üzerinde destek gruplarının etkisinin araştırıldığ1 çalışmada öznel iyi oluşun yaşam kalitesi üzerinde pozitif etkisi olduğu ve aile destek grup etkinliklerinin yaşam kalitesini yükselttiği sonucuna ulaşılmıştır (Shu \& Lung, 2005). Zihinsel engelli çocuklara sahip ailelerin yaşam kalitesinin incelendiği bir diğer çalısmada bedensel alan en yüksek ortalama olarak belirlenirken, çevresel alan en düşük ortalamaya sahip alt boyut olarak belirlenmiştir (Chou vd., 2007). Fiziksel aktivite durumlarına göre yapılan bu çalışmada en yüksek ortalamaya sahip sosyal alan ve en düşük ortalamaya sahip çevresel (Türkiye) alan ortaya çıkmıştır. Üniversite öğrencilerinde hastalık durumlarına göre yapılan bir çalışmada ise, sosyal alan ve çevresel alanın yüksek fiziksel aktivite düzeyi ile pozitif ilişkisi saptanmış, bedensel ve psikolojik alanın fiziksel aktivite ile ilişkisi bulunamıştır (Kılınç vd., 2016). Çalışma ile bedensel alan için paralel çerçevede çıkan bu araştırma sonuçlarında, psikolojik etmenler farklılık göstermiş ve anlamlı bulunmuştur. Akyıldız Munusturlar, (2016) ise fiziksel engellilerin ciddi boş zaman katulım derecelerine göre, bedensel, sosyal ve çevresel yaşam kalitesi alanlarında farklılık oluşmadığ1 belirtilmiştir. Çalışmaların aksine bir ila üç yıl arasında su cimnastiği aktivitelerine katılan yaşlı kadınların yalnızca bedensel alan yaşam kaliteleri katılmayanlara göre yüksek bulunmuştur (Garrido vd., 2016). Çalışmalar arası ortaya çıkan farklılıkların kişilerin içinde bulundukları sosyokültürel çevre, sosyoekonomik düzey ve yaşam kalitesinin kişilere göre değişen algılanma (Eser vd., 1999) sürecinden etkilendiği ve bunlara göre yaşam kalitesi alanlarına yönelik çıkan sonuçların farklılaştuğ1 düşünülmektedir.

Çalışmada fiziksel aktivite yapan ebeveynlerin (\%32.2), çoğunluğunun (\%20.7), haftada bir kez aktiviteye katıldığı saptanmıştır (Tablo 1). Bunun da yaşam kalitesi alt boyutlarından bedensel alanda anlamlı bir farklılığın bulunmasına etki etmediği; her gün aktiviteye katılanların ise anlamlı sonucun çıkmasında etkili olamayacak kadar küçük bir yüzdeye (\%7.9) sahip oldukları 
Karakaş, G., \& Yaman, Ç. (2017). Engelli bireye sahip ebeveynlerin fiziksel aktivite durumlarına göre yaşam kalitelerinin incelenmesi. Journal of Human Sciences, 14(1), 724-737. doi:10.14687/jhs.v14i1.4287

düşünülmektedir. Haftada bir kez katılımın kişilerin fiziksel sağlığını olumlu yönde etkileyebilecek bir süreyi teşkil etmediği, bedensel etkiyi yaratabilecek kadar uzun süre fiziksel aktivite yapılmamasından kaynaklandığı düşünülmektedir. Varolan sağlığı korumak ya da geliştirmek için fiziksel aktivitenin günde en az 30 dakika, orta şiddette (Haskell vd., 2007; Zorba, 2012) ve haftada 5 gün ya da daha fazla (Pate vd., 1995) yapılması tavsiye edilmektedir. Bu aktiviteler on dakikalık periyotlar halinde de yapilabilir. Fakat on dakikadan daha az olan aktivite periyotlarının etkisi görünmeyebilir. Önerilen fiziksel aktivitenin serbest zamanlarda yapılmasının yanı sıra ev işleri ya da ulaşımın fiziksel aktivite içeren hareketlerle yapılması da bu tavsiyenin içerisinde yer almaktadır (Haskell vd., 2007). Engelli çocuk sahibi ebeveynlerin sportif aktivite seviyelerinin yetersiz ve inaktivite olduğu, dolayısıyla da aile işlevlerine herhangi bir etkisinin olmadığ1 saptanmıştır (Kalkavan vd., 2011).

Engellilere yönelik 10 hafta boyunca yapılan egzersizlerde hem çocukların hem de ailelein yaşam kaliteleri incelenmiş ve egzersizin genel anlamda yaşam kalitesini etkilemediği ve 10 haftalık yapılan egzersiz süresinin yetersiz kaldığı, daha uzun süreyle çalışılması gerektiği vurgulanmıştır (Top ve Ak1l, 2017). Bu nedenle, şiddetli ve orta dereceli fiziksel aktiviteyi ve süresini arttırmak, sağlıkla ilişkili yaşam kalitesini yükseltmede etkin bir yöntem olabilir (Genç vd., 2011). Serbest zamanlarda yapılan fiziksel aktivite uzun bir zaman diliminde yapıldığında diğer gelişim alanlarından daha çok fiziksel gelişimle ilişkilendirilmektedir ve buna paralel olarak da uzun süreli aktiviteler fiziksel gelişim için koruyucu bir etki yaratmaktadır (Leino-Arjas vd., 2004). Aynı şekilde, yeteri kadar ve önerilen düzeyde fiziksel aktivite yapmamanın yaşam kalitesinin ruhsal alanında da fark yaratmadığı belirtilmiştir (Brown vd., 2006). Bir diğer çalışmada da, uzun süre yapılan fiziksel aktivitenin, yaşam kalitesinin ruh sağlığı, sosyal işlevsellik, zindelik gelişimiyle pozitif ilişkisi saptanmıştır (Wendel-Vos vd., 2004; Jurakic, Pedisic ve Greblo, 2010). Sağlıklı kişilerde yapılan çalışmada, üç yıl ve üzeri yapılan fiziksel aktivite ile yaşam kalitesinin fiziksel işlevsellik, zihinsel sağlık, sosyal işlevsellik ve zindelik altboyutları arasında sınırlı, zayıf ve pozitif bir ilişki saptanmıştır (Tessier vd., 2007). Ayrıca, uzun süreli sporla uğraşan kişilerde ve sporcularda postürde farkındalık ve düzgünlük değişkenleri, sedanterlere göre oldukça farklı bulunmuştur (Balc1 vd., 2007).

Kişilerin aktivite katılımlarında sürekliliği sağlamalarının onların bedensel yaşam kalitelerini arttıracağ1 ve diğer yaşam kalitelerinin de olumlu yönde daha da artacağ1 düşünülmektedir. Ateş, Saygın ve Zorba (2009) da fiziksel kapasite ve yaşam kalitesi arasında olumlu yönde bir ilişki olduğunu, sağılklı ve kaliteli bir yaşam için fiziksel kapasitenin önemli olduğunu vurgulamışlardır. Çünkü içerisinde daha fazla yoğunluk barındıran fiziksel aktivite, sağlık için daha çok yarar sağlar. Ancak yoğun fiziksel aktivitenin zaralı sonuçlanabilecek yönde olmaması için aktivite, kişinin sağlık durumuna göre değişkenlik gösterebilir (Haskell vd., 2007). Bununla beraber fiziksel olarak gereğinden fazla yüklenmek, aktivite yoğunluğunu ve şiddetini gereğinden fazla arttırmak olumlu değişiklikleri azaltabilir (Ruzic vd., 2003). Bu nedenle kişilerin kendi fiziksel kapasitelerine uygun şekilde ve düzeyde uzun süreli aktivite yapmalarının bedensel sağlık başta olmak üzere tüm sağlık alanlarını olumlu etkileyebileceği düşünülmektedir. Çoklu ve ağır zihinsel engelli çocukların annelerinin ev işlerine daha az zaman ayırdıkları bunun yanında çocuklarının bakımı için daha fazla zaman harcadıkları belirtilmiştir. Normal gelişim gösteren çocuğa sahip annelerden bir buçuk saat daha az serbest zamanları olduğu tespit edilmiştir (Luijkx, Putten ve Vlaskamp, 2017).

Sonuç olarak, fiziksel aktivite yapan ebeveynlerin yaşam kalitelerinin ve fiziksel aktivite düzeylerinin daha yüksek olduğu bunun sonucunda da çocukları için daha güzel ve sağllklı bir yaşam sunacakları düşünülmektedir. Aileleri bu konuda bilinçlendirmek ve yönlendirmek onların daha sağlıklı aileler olarak yaşamasına ve sağlıklı bireyler yetiştirmesine imkân sağlamak için atılması gereken ilk adım olarak düşünülmektedir. 
Karakaş, G., \& Yaman, C.. (2017). Engelli bireye sahip ebeveynlerin fiziksel aktivite durumlarına göre yaşam kalitelerinin incelenmesi. Journal of Human Sciences, 14(1), 724-737. doi:10.14687/jhs.v14i1.4287

\section{Kaynaklar}

Akyldız Munusturlar, M. (2016). Examınation of the serious leisure, leisure satisfaction and quality of life of people with physical disabilities. Sport Sciences (NWSASPS), 11(3): 23-38. http://dx.doi.org/10.12739/NWSA.2016.11.3.2B0105.

Allik, H., Larsson, J. \& Smedje, H. (2006). Health-related quality of life in parents of school- age children with asperger syndrome or highfunctioning autism. Health and Quality of Life Outcomes. 4: 1. doi: 10.1186/1477-7525-4-1.

Alpar, R. (2012). Spor, Sağhlk ve Eğitim Bilimlerinden Örneklerle Uygulamal İstatistik ve Geçerlik-Güvenirlik. (1. Basım). Ankara: Detay Yayıncilik.

Altun, B., Bayramlar, K., Kayıhan, G. \& Ergun, N. (2011). Bedensel engellilerin sportif aktivitelere katılımının yaşam kalitesi üzerine etkisi. Selçuk. Üniversitesi Beden Eğitimi ve Spor Bilim Dergisi, 13 (Ek Say1), 161-164.

Aras, I., Stevanovic, R., Vlahovic, S., Stevanovic, S., Kolaric, B. \& Kondic, L. (2014). Health related quality of life in parents with speech and hearing impairment. International Journal of Pediatric Otorbinolaryngology. 78: 323-329. doi: 10.1016/j.ijporl.2013.12.001.

Arslan. C.. Güllü. M. \& Tutal V. (2011). Spor yapan ve yapmayan ilköğretim öğrencilerinin depresyon durumlarının bazı değişkenlere göre incelenmesi. Niğde Üniversitesi Beden Eğitimi ve Spor Bilimleri Dergisi, 5 (2). 120-132.

Ateş. B.. Saygın. Ö. \& Zorba. E. (2009). Ev hanımlarının fiziksel kapasitelerinin ve yaşam kalitelerinin belirlenmesi. Uluslararasi Insan Bilimleri Dergisi. 6 (2). 357-367.

Aysan, F. \& Özben, Ş. (2007). Engelli çocuğu olan anne babaların yaşam kalitelerine ilişkin değişkenlerin incelenmesi. Dokuz Eylül Üniversitesi Buca Eğitim Fakültesi Dergisi, 22, 1-6.

Baghdadli, A., Pry, R., Michelon, C. \& Rattaz, C. (2014). Impact of autism in adolescents on parental quality of life. Quality of Life Research. 23: 1859-1868. doi: 10.1007/s11136-014-0635-6

Balcı. P.. Sertoğlu. E.. Irmak. R. \& Baltacı. G. (2007). Sporcu ve sedanter bireyler arasındaki postüral farkliliklar.Fizyoterapi Rehabilitasyon Dergisi, 18(2). 85-166.

Benjak, T. (2011). Subjective quality of life for parents of children with autism spectrum disorders in Croatia. Applied Research in Quality of Life. 6: 91-102. DOI: 10.1007/s11482-010-9114-6.

Boylu, A. \& Terzioğlu, G. (2007). Ailelerin yaşam kalitelerini etkileyen bazı objektif ve sübjektif göstergelerin incelenmesi. T.C. Başbakanlık Aile ve Soysal Araşttrmalar Genel Müdürlügüu Yayınları. Ankara.

Brown, R.I., MacAdam-Crisp, J., Wang, M. \& Iarocci, G. (2006). Family quality of life when there is a child with a developmental disability. Journal of Policy and Practice in Intellectual Disabilities, 3 (4): 238-245. DOI: $10.1111 /$ j.1741-1130.2006.00085.x.

Cengiz, C. (2007). Physical activity and exercise stages of change levels of Middle East Technical University students. Yaymlanmamıs yüksek lisans teæri. Orta Doğu Teknik Üniversitesi Beden Eğitimi ve Spor Bölümü: Ankara.

Chou, Y.C., Lin, L., Chang, A. \& Schalock, R. L. (2007). The quality of life of family caregivers of adults with intellectual disabilities in Taiwan. Journal of Applied Research in Intellectual Disabilities, 20, 200 210. DOI:10.1111/j.1468-3148.2006.00318.x

Çalışkan, E. (2011). Engelli çocuklarda spor eğitimi ve ailelerin yaklaşımları. 1. Uluslararası Katılıml Engellilerde Beden Eğitimi ve Spor Kongresi Kitabı. Selçuk Üniversitesi Beden Eğitimi ve Spor Yüksekokulu. Konya. http://sporbilim.com/dosyalar/kongrekt.pdf

Dahan-Oliel, N., Shikako-Thomas, K. \& Majnemer, A. (2012). Quality of life and leisure participation in children with neurodevelopmental disabilities: a thematic analysis of the literature. Qual Life Res,21:427-439. DOI 10.1007/s11136-011-0063-9.

Dardas, L. A. \& Ahmad, M. M. (2013). Coping strategies as mediators and moderators between stress and quality of life among parents of children with autistic disorder. Stress Health,31:5-12. DOI:10.1002/smi.2513.

Dardas, L. A. \& Ahmad, M. M. (2014a). Quality of life among parents of children with autistic disorder: A sample from the arab world. Research in Developmental Disabilities, 35 (2014) 278-287. http://dx.doi.org/10.1016/j.ridd.2013.10.029 
Karakaş, G., \& Yaman, Ç. (2017). Engelli bireye sahip ebeveynlerin fiziksel aktivite durumlarına göre yaşam kalitelerinin incelenmesi. Journal of Human Sciences, 14(1), 724-737. doi:10.14687/jhs.v14i1.4287

Dardas, L. A. \& Ahmad, M. M. (2014b). Validation of the world health organization's quality of life questionnaire with parents of children with autistic disorder. Journal of Autism and Developmental Disorders, Volume 44, Issue 9, pp 2257-2263. DOI: 10.1007/s10803-014-2110-1

Eapen, V. \& Guan, J. (2016). Parental quality of life in autism spectrum disorder: Current status and future directions. Acta Psychopathol. 2:1. DOI: 10.4172/2469-6676.100031.

Eapen, V., Črnčec, R. Walter, A. \&Tay, K. P. (2014). Conceptualisation and development of a quality of life measure for parents of children with autism spectrum disorder. Autism Research and Treatment, Volume 2014, Article ID 160783. http://dx.doi.org/10.1155/2014/160783

Elley, C. R., Kerse, N., Arroll, B., Robinson, E. (2003). Effectiveness of counselling patients on physical activity in general practice: Cluster randomised controlled trial. BMJ, 326, 793. doi.org/10.1136/bmj.326.7393.793.

Erdoğanoğlu, Y. \& Kerem Günel, M. (2007). Serebral paralizili çocukların ailelerinin sağlıkla ilgili yaşam kalitelerinin araşturilması. Toplum Hekimlï̆i Bülteni, Cilt 26, Sayı 2.

Eser, E., Fidaner, H., Fidaner, C., Elbi, H. \& Göker, E. (1999). WHOQOL-100 ve WHOQOL-Bref in psikometrik özellikleri. 3p Dergisi, 7. 23-40.

Fisher, K. J. \& Li, F. (2004). A community-based walking trial to improve neighborhood quality of life in older adults: A multilevel analysis. Ann. Behav. Med. 28,186-194. DOI: 10.1207/s15324796abm2803_7.

Garrido, N., Silva, J. D. P., Novaes, J. S., Cirilo-Sousa, M. S. \& Neto, G. R. (2016). Effect of water aerobics on the quality of life, satisfaction, and perception of body image among elderly women. Journal of Exercise Physiology online. 19(5):30-37.

Genç, M., Şener, Ü., Karabacak H. \& Üçok, K. (2011). Kadın ve erkek genç erişkinler arasında fiziksel aktivite ve yaşam kalitesi farklılıklarının araştırılması. Kocatepe Tip Dergisi, 12, 145-150.

Gomez, I. N. B. \& Gomez, M. G. (2013). Quality of life of parents of filipino children with special needs. Education Quarterly, Vol 71, Issue 2 pp. 42-58.

Haskell, W. L., Lee, I. M., Pate, R. R., Powell, K. E., Blair, S. N., Franklin, B. A., Macera, C. A., Heath, G. W., Thompson, P. D. \& Bauman, A. (2007). Physical activity and public health-Updated recommendation for adults from the American college of sports medicine and the American heart association. Medicine \& Science in Sports \& Exercise.39(8):1423-34. DOI: 10.1249/mss.0b013e3180616b27.

Johnson, N., Frenn, M., Feetham, S. \& Simpson, P. (2011). Autism spectrum disorder: Parenting stress, family functioning and health-related quality of life. Families, Systems and Health. 29: 232-252. doi: $10.1037 / \mathrm{a} 0025341$.

Jurakic, D., Pedisic, Z. \& Greblo, Z. (2010). Physical activity in different domains and health-related quality of life: a population-based study. Qual Life Res, 19:1303-1309. DOI 10.1007/s11136010-9705-6.

Kalkavan, A., Demirel, M., Eynur, B. R., Deirel, H. D., Eynur, A. \& Gözeltepe, Z. (2011). Engelli çocuk sahibi ailelerin sportif faaliyetlere katılımının aile işlevlerine etkisinin incelenmesi. Selçuk. Üniversitesi Beden Eğitimi ve Spor Bilim Dergisi, 13 (Ek Say1), 214-219.

Kılınç, H., Bayrakdar, A., Çelik, B., Mollaoğulları, H. \& Gencer, Y. G. (2016). Üniversite öğrencilerinde fiziksel aktivite düzeyi ve yaşam kalitesi. Journal of Human Sciences, 13(3), 3794-3806. doi:10.14687/jhs.v13i3.3841.

Lee, G. K., Lopata, C., Volker, M. A., Thomeer, M. L., Nida, R. E., Toomey, J. A., Chow, S. Y. \& Smerbeck, A. M. (2009). Health-related quality of life of parents of children with highfunctioning autism spectrum disorders. Focus on Autism and Other Developmental Disabilities, 24(4), 227-239. DOI: $10.1177 / 1088357609347371$.

Leino-Arjas, P., Solovieva, S., Riihimaki, H., Kirjonen, J., Telama, R. (2004). Leisure time physical activity and strenuousness of work as predictors of physical functioning: a 28 year follow up of a cohort of industrial employees. Occup. Environ. Med. 61(12), 1032-1038. doi: 10.1136/oem.2003.012054.

Leung, C. Y. S. \& Li-Tsang, C. W. P. (2003). Quality of life of parents who have children with disabilities. Hong Kong Journal of Occupational Therapy,Volume 13, Issue 1, Pages 19-24. doi:10.1016/S1569-1861(09)70019-1. 
Karakaş, G., \& Yaman, Ç. (2017). Engelli bireye sahip ebeveynlerin fiziksel aktivite durumlarına göre yaşam kalitelerinin incelenmesi. Journal of Human Sciences, 14(1), 724-737. doi:10.14687/jhs.v14i1.4287

Lin, J., Hu, J., Yen, C., Hsu, S., Lin, L., Loh, C., Chen, M., Wu, S., Chu, C. M. \& Wu, J. (2009). Quality of life in caregivers of children and adolescents with intellectual disabilities: Use of WHOQOLBREF survey. Research in Developmental Disabilities, 30, 1448-1458. doi:10.1016/j.ridd.2009.07.005.

Luijkx, J., Putten, A. A. J., \& Vlaskamp, C. (2017). Time use of parents raising children with severe or profound intellectual and multiple disabilities. Child: Care, Health and Development. doi:10.1111/cch.12446.

Marchal, J.P., Maurice-Stam, H., Hatzmann, J., Trotsenburg, P. \& Grootenhuis, M. A. (2013). Health related quality of life in parents of six to eight year old children with down syndrome. Research in Developmental Disabilities, 34 (11), 4239-4247. http://dx.doi.org/10.1016/j.ridd.2013.09.011

Meral, B. F. \& Cavkaytar, A. (2014).Otizmli çocuk ailelerinin aile yaşam kalitesi algılları. Kastamonu Eğitim Dergisi, 23 (3), 1363-1380.

Modesta Pousada, M., Guillamón, N., Hernández-Encuentra, E., Muñoz, E., Redolar, D., Boixadós, M. \& Gómez-Zúñiga, B. (2013). Impact of caring for a child with cerebral palsy on the quality of life of parents: A systematic review of the literature. Journal of Developmental and Physical Disabilities, Volume 25, Issue 5, pp 545-577. DOI: 10.1007/s10882-013-9332-6.

Mugno, D., Ruta, L., D'arrigo, V. G. \& Mazzone, L. (2007). Impairment of quality of life in parents of children and adolescents with pervasive developmental disorder. Health and Quality of Life Outcomes, 5:22, doi:10.1186/1477-7525-5-22.

Ngai, F. \& Fei Ngu, S. (2013). Family sense of coherence and quality of life. Qual Life Res, 22:20312039. DOI 10.1007/s11136-012-0336-y.

Omorou, Y. A., Erpelding, M., Escalon, H. \& Vuillemin, A. (2013). Contribution of taking part in sport to the association between physical activity and quality of life. Qual Life Res,22:2021-2029. DOI 10.1007/s11136-013-0355-3.

Özay, H. (2004). Ailenin çocuğa ilişkin kabul ve beklenti düzeyleri. 3. Ulusal Özel Eğitim Kongresi Bildirileri Özৃel Ë̆itimden Yansimalar. A. Konrot (Editör), (Birinci Baskı), Ankara: Kök Yayıncilık.

Özşenol, F., Işıkhan, V., Ünay, B., Aydın, İ. A., Akın, R. \& Gökçay, E. (2003). Engelli çocuğa sahip ailelerin aile işlevlerinin değerlendirilmesi. Gülhane Tip Dergisi, 45 (2). 156-164. http:/ /www.scopemed.org/fulltextpdf.php?mno $=5058$.

Öztürk. M. (2005). Üniversite eğitim gören öğrencilerde uluslararası fiziksel aktivite anketinin geçerliliği ve güvenirliği ve fiziksel aktivite düzeylerinin belirlenmesi.Yaynlanmamıs yülksek lisans ter̨i. Hacettepe Üniversitesi Sağlık Bilimleri Enstitüsü: Ankara.

Pate, R. R., Pratt, M., Blair, S. N., Haskell, W. L., Macera, C. A., Bouchard, C., Buchner, D., Ettinger, W., Heath, G. W., King, A. C., Kriska, A., Leon, A. S., Marcus, B. H., Morris, J., Paffenbarger, R. S., Patrick, K., Pollock, M. L., Rippe, J. M., Sallis, J. \& Wilmore, J. H. (1995). Physical activity and public health: A recommendation from the centers for disease control and prevention and the american college of sports medicine. JAMA. 273(5):402-407. doi:10.1001/jama.1995.03520290054029.

Pozo, P., Sarriá, E. \& Brioso, A. (2014). Family quality of life and psychological well-being in parents of children with autism spectrum disorders: A double ABCX model. Journal of Intellectual Disability Research. 58: 442-458. doi: 10.1111/jir.12042.

Ruzic, L., Heimer, S., Misigoj-Durakovic, M., Matkovic, B.R., (2003). Increased occupational physical activity does not improve physical fitness. Occup. Environ. Med. 60, 983-985. doi: 10.1136/oem.60.12.983.

Sapancalı, F. (2009). Toplumsal açıdan yaşam kalitesi. İzmir: Altın Nokta Basım Yayın Dağıım.

Sevindi, T., Keskin, A., Gördeles Beşer, N. \& Eker H. (2010). Spor faaliyetlerinin engelli bireylerin aile sürecine etkisinin incelenmesi. Selcuk Üniversitesi Beden Eg̈itimi ve Spor Bilim Dergisi, 12 (1), 12-19.

Shu, B. C. \& Lung, F. W. (2005). The effect of support group on the mental health and quality of life for mothers with autistic children. Journal of Intellectual Disability Research, 49(1), 47-53. DOI:10.1111/j.1365-2788.2005.00661.x.

Siah, P. C. \&. Tan, S. H. (2016). Relationships between Sense of coherence, coping strategies and quality of life of parents of children with autism in Malaysia: A study of chinese parents. Disability, CBR \& Inclusive Development, Vol. 27, No.1; doi 10.5463/DCID.v27i1.485. 
Karakaş, G., \& Yaman, Ç. (2017). Engelli bireye sahip ebeveynlerin fiziksel aktivite durumlarına göre yaşam kalitelerinin incelenmesi. Journal of Human Sciences, 14(1), 724-737. doi:10.14687/jhs.v14i1.4287

Spirduso, W. W. \& Cronin, D. L. (2001). Exercise dose-response effects on quality of life and independent living in older adults. Med. Sci. Sports Exerc. 33, 598-S608.

Tekkanat, Ç. (2008). Öğretmenlik bölümünde okuyan öğrencilerde yaşam kalitesi ve fiziksel aktivite düzeyleri. Yayınlanmamıs yülksek lisans tęi. Pamukkale Üniversitesi Sağllk Bilimleri Enstitüsü: Denizli.

Tessier, S., Vuillemin, A., Bertrais, S., Boini, S., Bihan, E., Oppert, J., Hercberg, S., Guillemin, F. \& Briançon, S. (2007). Association between leisure-time physical activity and health-related quality of life changes over time. Preventive Medicine. 44, 202-208. doi:10.1016/j.ypmed.2006.11.012.

Top. E. \& Akıl, M. (2017). 10 haftalık yüzme egzersizinin hafif düzeyde zihinsel engelli bireyler ve ailelerinin yaşam kalitelerine etkisi. Journal of Sports and Performance Researches. 8, 1. Do1: 10.17155/spd.91688.

Tung, L., Huang, C., Tseng, M., Yen, H., Tsai, Y., Lin, Y., Chen, K. (2014). Correlates of health- related quality of life and the perception of its importance in caregivers of children with autism. Research in Autism Spectrum Disorders. 8: 1235-1242. http://dx.doi.org/10.1016/j.rasd.2014.06.010.

Vergili, Ö., Oktaş, B., Koçulu, E. (2015). Engelli çocuğun bağımsızlık düzeyinin kendisine bakım verenler üzerindeki sağlıkla ilgili yaşam kalitesi açısından etkisinin incelenmesi, Hacettepe University Faculty of Health Sciences Journal. 1 (1): 1-7.

Wendel-Vos, G. C., Schuit, A. J., Tijhuis, M. A., Kromhout, D. (2004). Leisure time physical activity and health-related quality of life: Cross-sectional and longitudinal associations. Qual. Life Res, 13, 667-677. DOI: 10.1023/B:QURE.0000021313.51397.33.

Zorba, E. \& Saygin, Ö. (2009). Fizilesel Aktivite ve Fiz̨iksel Uygunluk.(2. Basım) İstanbul: İnceler Ofset Matbaa.

Zorba, E. (2012). Herkes İ̧̧in Yaşam Boyu Spor. (3. Basım) Ankara: Neyir Yayınları.

\section{Extended English Abstract}

Children with disabilities who are participating in the family or those who are disabled later create additional stress to the mother and child. One of the reasons for the additional source of stress in these emotions and thoughts is the pressure caused by a perception of disability in the society. When the society sees an individual with a disability, the psychological pressure it creates on the parents with prejudices such as pity, not approaching the side, "Is this also infect my child?" thoughts. Having a disabled child aside from thinking "How to meet in society?" it is a very difficult process for parents to acknowledge and overcome this situation on their own. The current situation restricts the ability of parents with disabilities and the disabled individual to meet the necessary psychological needs, such as the opportunities to enjoy life, motivation, self-sacrifice. This reduces the quality of life. According to Boylu and Terzioğlu (2007) family life quality, meeting the needs of family members, living together as a family, having meaningful goals for family members and reaching them. However, parents and children with disabilities can move away from these problems, both within the family and within society, by moving to different activities. While there have been many studies exploring the quality of life of families of disabled and autistic individuals (Leung \& Li-Tsang 2003; Aysan \& Özben 2007; Erdoğanoğlu \& Kerem Günel, 2007; Mugno vd. 2007; Chou, vd. 2007; Lin, 2009; Dardas ve Ahmad 2013; Modesta Pousada vd. 2013; Marchal vd. 2013; Gomez \& Gomez, 2013; Eapen, Črnčec, Walter, \&Tay, 2014; Meral \& Cavkaytar, 2014; Dardas ve Ahmad 2014a; Dardas ve Ahmad 2014b; Siah\&Tan, 2016); It is seen that there is no work to study the quality of life on this mass by associating it with sports sciences. Physical activity, which is a positive touch to the quality of life of parents; It is a basic field that allows parents to participate, recreationally or professionally as a profession, and to relax, social, physical, mental and psychological. Physical activity is also a form of life that raises the quality of life and is happy and peaceful for families. Mothers and fathers can improve their quality of life as a result of overcoming these problems by doing physical activity. 
Karakaş, G., \& Yaman, Ç. (2017). Engelli bireye sahip ebeveynlerin fiziksel aktivite durumlarına göre yaşam kalitelerinin incelenmesi. Journal of Human Sciences, 14(1), 724-737. doi:10.14687/jhs.v14i1.4287

In this respect, in this research it was aimed to examine of the quality of life according to physical activity status of parents who have disabled individual.. In the study using the descriptive survey model, convenience sampling was used for the creation of the sample. The parents of 164 disabled individuals (132 mother; $\bar{x}=40,5 \pm 8,90)$ ve 32 father; $\bar{x}=46,21 \pm 9,74)$ who attended to various special education institutions in Sakarya province participated in the research. Parents who participated in the study were included in the study to have children with autism (25.6\%), mental $(41.5 \%)$, visually $(2.4 \%)$, hearing $(15.2 \%)$ and physically handicapped $(15.2 \%)$. In this study, a Family Information Form, which was prepared by the researcher, was used to reach the demographic informations of parents. In the form prepared by the researcher, besides the information about the parents, contains questions about the disabled individual to access the information. This information form is also filled by the mother or father who cares of the child. With the aim of measuring the quality of life in parents, World Health Organization Quality of LifeBref Form (WHOQOL-BREF), which was adopted to Turkish by Eser and his friends (1999) and for measuring the level of physical activity of parents, International Physical Activity QuestionnaireShort Form (IPAQ), which was adoped to Turkish by Öztürk (2005) were used in the study. WHOQOL-BREF scale consists of 5 sub-dimensions including the physical area, psychological area, social area, environmental area and environmental TR area created by adding a question in Turkish adaptation and 27 questions. The Cronbach's alpha coefficient of physical area subscale is .77., psychological area subscale is .71, social area is .61, environmental area is .81 and environmental area Turkey is .78. IPAQ self-administered 'last 7 days' short form was used in this study. The form provides information on time spent on walking, moderate-severe and violent activities. The calculation of the total score of the short form is based on the sum of time (minutes) and frequency (days) (Öztürk, 2005). From these calculations, a score of MET-minutes is obtained and the MET term is used, which is abbreviated as Metabolic Equivalent (metabolic equivalent) to express the amount of oxygen consumed during physical activity (Zorba \& Sayg1n, 2009). Before the questionnaires were applied, the content of the study, the informations about the questionnaires and application had been transferred to the parents by the researcher and with this, the joining of the parents to the study was carried out voluntarily. After the descriptive statistical processes had been applied in the analysis of datas, an independent t-test and chi-square test to detect from which groups the differences between the groups originate. Data was evaluated by using SPSS for Windows 15 software.

In a study conducted to investigate the effect of physical activity on the quality of life of parents with disabilities, it was found that all areas of the physical activity parents except the physical area and the physical activity levels were higher than the non-sports parents. Therefore, it can be said that physical activity affects psychological, social and environmental quality of life positively. The positive effect of physical activity and sport participation on all individuals should not be overlooked. Participation in sports has been noted in a variety of studies that have positive effects on all individuals and all areas of quality of life (Boylu ve Terzioğlu, 2007; Kalkavan vd., 2011; Altun vd., 2011).

As a result, the fact that the quality of life parents who have disabled individual and doing sport was found to be at a higher level of those who have individual but not doing sport. In addition to this doing sport was detected to increase the quality of life parents who have a disabled individual. As a result, it is thought that the parents of physically active parents have higher quality of life and physical activity levels and as a result they will provide a better and healthier life for their children. Their families are thought to be the first step in raising awareness and guiding them in order to enable them to live as healthy families and to raise healthy individuals. 